\title{
Correction to: GALP: a hybrid artificial intelligence algorithm for generating covering array
}

\author{
Sajad Esfandyari ${ }^{1}$ (1) Vahid Rafe $^{1}$
}

Published online: 5 May 2021

(C) Springer-Verlag GmbH Germany, part of Springer Nature 2021

\section{Correction to: Soft Computing}

https://doi.org/10.1007/s00500-021-05788-0

While typesetting the article the below references are published without surname. The correct references are copied below.

1. Ahmed BS, Zamli KZ, Lim CP (2012) Application of particle swarm optimization to uniform and variable strength covering array construction. Appl Soft Comput 12(4):1330-1347.

2. Ahmed BS, Abdulsamad TS, Potrus MY (2015) Achievement of minimized combinatorial test suite for configuration-aware software functional testing using the Cuckoo Search algorithm. Inf Softw Technol 66:13-29.

3. Calvagna A, Gargantini A (2009) IPO-s: incremental generation of combinatorial interaction test data based on symmetries of covering arrays. In: International conference on software testing, verification, and validation workshops, Denver, CO, USA.

4. Hartman A (2005) Software and hardware testing using combinatorial covering suites, vol 34. Springer, Berlin.

5. Hartman A (2019) IBM intelligent test case handler. IBM alphaworks. http://www.alphaworks.ibm.com/tech/ whitch

6. Jenkins B (2019) Jenny download web page. Bob Jenkins' Website. http://burtleburtle.net/bob/math/jenny. html

7. Kuhn DR (2019) ACTS page download. http://csrc. nist.gov/groups/SNS/acts/download_tools.html

8. Zamli KZ, Din F, Kendall G, Ahmed BS (2017a) An experimental study of hyper-heuristic selection and acceptance mechanism for combinatorial t-way test suite generation. Inf Sci 399:121-153.

The original article has been updated.

Publisher's Note Springer Nature remains neutral with regard to jurisdictional claims in published maps and institutional affiliations.

The original article can be found online at https:// doi.org/10.1007/s00500-021-05788-0.

Sajad Esfandyari

Sajad.a1367@gmail.com

Vahid Rafe

v-rafe@araku.ac.ir

1 Department of Computer Engineering, Faculty of Engineering, Arak University, Arak 38156-8-8349, Iran 